\title{
Editorial \\ Study of Rechargeable Batteries Using Advanced Spectroscopic and Computational Techniques
}

\author{
Bernardo Barbiellini ${ }^{1,2, *(\mathbb{D}}$, Jan Kuriplach ${ }^{3(\mathbb{D}}$ and Rolando Saniz ${ }^{4}$ \\ 1 Department of Physics, School of Engineering Science, LUT University, FI-53851 Lappeenranta, Finland \\ 2 Department of Physics, Northeastern University, Boston, MA 02115, USA \\ 3 Department of Low Temperature Physics, Faculty of Mathematics and Physics, Charles University, \\ V Holešovičkách 2, CZ-180 00 Prague, Czech Republic; Jan.Kuriplach@mff.cuni.cz \\ 4 Departement Fysica, Universiteit Antwerpen, Groenenborgerlaan 171, B-2020 Antwerpen, Belgium; \\ rolando.saniz@uantwerpen.be \\ * Correspondence: Bernardo.Barbiellini@lut.fi
}

\section{check for}

updates

Citation: Barbiellini, B.; Kuriplach, J.; Saniz, R. Study of Rechargeable Batteries Using Advanced Spectroscopic and Computational Techniques. Condens. Matter 2021, 6, 26. https://doi.org/10.3390/ condmat6030026

Received: 16 July 2021

Accepted: 19 July 2021

Published: 25 July 2021

Publisher's Note: MDPI stays neutral with regard to jurisdictional claims in published maps and institutional affiliations.

Copyright: (c) 2021 by the authors. Licensee MDPI, Basel, Switzerland. This article is an open access article distributed under the terms and conditions of the Creative Commons Attribution (CC BY) license (https:// creativecommons.org/licenses/by/ $4.0 /)$.

\begin{abstract}
Improving the efficiency and longevity of energy storage systems based on Li- and Na-ion rechargeable batteries presents a major challenge. The main problems are essentially capacity loss and limited cyclability. These effects are due to a hierarchy of factors spanning various length and time scales, interconnected in a complex manner. As a consequence, and in spite of several decades of research, a proper understanding of the ageing process has remained somewhat elusive. In recent years, however, combinations of advanced spectroscopy techniques and first-principles simulations have been applied with success to tackle this problem. In this Special Issue, we are pleased to present a selection of articles that, by precisely applying these methods, unravel key aspects of the reduction-oxidation reaction and intercalation processes. Furthermore, the approaches presented provide improvements to standard diagnostic and characterisation techniques, enabling the detection of possible Li-ion flow bottlenecks causing the degradation of capacity and cyclability.
\end{abstract}

Keywords: Li-ion battery; Na-ion battery; Li-air battery; spectroscopy techniques for batteries; firstprinciples calculations; cathode materials; anode materials; electrolytes; Li diffusion and intercalation

\section{Introduction}

Energy storage systems are commonplace in small handheld devices, but they are being used more and more as a power source in larger scale applications, as an alternative or complement to fossil fuels. Examples include electric vehicles and balancing in electrical power grids. Li-ion battery (LIB) technology [1-4] is largely used for such applications. This technology, however, has several shortcomings, the most important being its limited energy density and lifetime, the latter currently in the range of a few years. Hopes are high for other technologies as well, such as Na-ion, Li-air and Li-sulphur batteries [5]. However, the understanding of the functioning of these technologies and of the related obstacles to their wider adoption is still lacking. This holds in many respects for LIB technologies as well. The objective of current research is to provide answers to the basic questions posed by the ageing mechanisms in Li-ion batteries [6]: How to detect early signs and what are the reasons for the degradation of a battery? How to improve the lifetime of a battery? How to recycle the expensive battery packs, making the best use of their possible second life? Answering these questions in a way relevant to the lithium industry can have important societal impacts $[7,8]$. The challenges in this endeavour are many. It is important to first realise that the challenges faced present a complexity implicating a hierarchy of scales, i.e., from the atomic scale [9] to the macroscopic scale [10]. Their study calls for joint experimental and theoretical work, as well as an interdisciplinary approach, involving physics, chemistry, materials science, and engineering, as the various scale hierarchies are coupled to each other and to the functionality of the Li-ion batteries in an intricate manner. 
The research activities reported in this Special Issue tackle these challenges at different levels using various approaches.

\section{Advanced Battery Characterisation}

In situ and in operando $X$-ray techniques available at synchrotron radiation facilities provide powerful tools for battery material research, allowing a deep understanding of structural evolution, redox processes, and transport properties during cycling [11], and present us with a new avenue for battery technology characterisation [12]. As an example, in operando X-ray diffraction (XRD) and X-ray absorption have been useful to understand the reversible electrochemical lithiation of potassium iron hexacyanocobaltate [13]. Moreover, X-ray resonant inelastic scattering (RIXS) at the oxygen K edge is an experimental soft $X$-ray technique capable of directly probing the oxygen activity in the redox processes [14]. On the other hand, the use of high-energy $X$-ray scattering at synchrotron radiation facilities has enabled the study of the electronic wavefunctions associated with redox processes by means of Compton scattering [9,15-17]. An advantage of X-ray Compton scattering is that it can be effectively applied to commercial batteries, thanks to the high penetration power of high-energy X-rays $[18,19]$. In addition, the large reciprocal space range accessible to high-energy $\mathrm{X}$-rays allows acquiring total scattering data for the analysis of the pair distribution function to study battery materials having short-range order only [20].

The role of internal interfaces in Li migration occurring in Li-ion batteries can be studied using first-principles simulations based on density functional theory (DFT) combined with positron annihilation spectroscopy [21]. The latter can be viewed as a cousin technique of Compton scattering, involving $\gamma$-rays instead of hard X-rays, allowing the identification of defects (that are often attractive for positrons) and their chemical surroundings in materials [22,23]. DFT-based simulations in conjunction with Mössbauer spectroscopy, moreover, can be applied to study the deep connection between magnetism, electronic, and atomic structure in cathode materials [24] allowing the identification of the redox state of cathodes. DFT-based simulations are also able to provide precious information regarding the effect of the local atomic environment and structural deformations on the electrochemical redox potentials [17]. This is well illustrated further by a computational study of the electrochemical potentials in a metal-organic framework used as cathode for Li-ion batteries [25]. In addition, DFT-based methods are used to explain the experimentally measured conductivity and capacity of anode materials, such as in high-capacity Na-ion batteries [26]. Most interestingly, such methods have also shown the potential of topological materials, such as $\mathrm{Na}_{3} \mathrm{Bi}$, to be used as anode materials [27].

\section{Conclusions}

The results presented in this Special Issue show important advances in research on rechargeable batteries. We can look into the mechanisms at the heart of battery technologies by applying a combination of quantum mechanical calculations and spectroscopic techniques, practically reconstructing the redox processes. The ultimate goal of this body of research is the development of a probe ensemble capable of visualising lithium insertion in real time and on an atomic scale, in order to enable systematic routes to better battery diagnostics and to improve the efficiency and performance of batteries.

Author Contributions: All the authors contributed equally. All authors have read and agreed to the published version of the manuscript.

Funding: This research was supported by the Ministry of Education and Culture (Finland).

Acknowledgments: We express our thanks to all authors that contributed to this Special Issue, to the journal Condensed Matter that hosts these contributions and to the MDPI staff for their continuous support.

Conflicts of Interest: The authors declare no conflict of interest. 


\section{References}

1. Goodenough, J.B. How we made the Li-ion rechargeable battery. Nat. Electron. 2018, 1, 204. [CrossRef]

2. Assat, G.; Tarascon, J.M. Fundamental understanding and practical challenges of anionic redox activity in Li-ion batteries. Nat. Energy 2018, 3, 373-386. [CrossRef]

3. Winter, M.; Barnett, B.; Xu, K. Before Li ion batteries. Chem. Rev. 2018, 118, 11433-11456. [CrossRef] [PubMed]

4. Mauger, A.; Julien, C.M.; Goodenough, J.B.; Zaghib, K. Tribute to Michel Armand: from rocking chair-Li-ion to solid-state lithium batteries. J. Electrochem. Soc. 2019, 167, 070507. [CrossRef]

5. Pellegrini, V.; Bodoardo, S.; Brandell, D.; Edström, K. Challenges and perspectives for new material solutions in batteries. Solid State Commun. 2019, 303, 113733. [CrossRef]

6. Vetter, J.; Novák, P.; Wagner, M.R.; Veit, C.; Möller, K.C.; Besenhard, J.; Winter, M.; Wohlfahrt-Mehrens, M.; Vogler, C.; Hammouche, A. Ageing mechanisms in lithium-ion batteries. J. Power Sources 2005, 147, 269-281. [CrossRef]

7. Quinteros-Condoretty, A.R.; Albareda, L.; Barbiellini, B.; Soyer, A. A Socio-technical transition of sustainable lithium industry in Latin America. Procedia Manuf. 2020, 51, 1737-1747. [CrossRef]

8. Quinteros-Condoretty, A.R.; Golroudbary, S.R.; Albareda, L.; Barbiellini, B.; Soyer, A. Impact of circular design of lithium-ion batteries on supply of lithium for electric cars towards a sustainable mobility and energy transition. Procedia CIRP 2021, 100, 73-78. [CrossRef]

9. Hafiz, H.; Suzuki, K.; Barbiellini, B.; Tsuji, N.; Yabuuchi, N.; Yamamoto, K.; Orikasa, Y.; Uchimoto, Y.; Sakurai, Y.; Sakurai, H.; et al. Tomographic reconstruction of oxygen orbitals in lithium-rich battery materials. Nature 2021, 594, 213-216. [CrossRef]

10. Suzuki, K.; Suzuki, S.; Otsuka, Y.; Tsuji, N.; Jalkanen, K.; Koskinen, J.; Hoshi, K.; Honkanen, A.P.; Hafiz, H.; Sakurai, Y.; et al. Redox oscillations in 18650-type lithium-ion cell revealed by in operando Compton scattering imaging. Appl. Phys. Lett. 2021, 118, 161902. [CrossRef]

11. Huang, W.; Marcelli, A.; Xia, D. Application of synchrotron radiation technologies to electrode materials for Li-and Na-ion batteries. Adv. Energy Mater. 2017, 7, 1700460. [CrossRef]

12. Llewellyn, A.V.; Matruglio, A.; Brett, D.J.L.; Jervis, R.; Shearing, P.R. Using in-situ laboratory and synchrotron-based X-ray diffraction for lithium-ion batteries characterization: A review on recent developments. Condens. Matter 2020, 5, 75. [CrossRef]

13. Mullaliu, A.; Conti, P.; Aquilanti, G.; Plaisier, J.R.; Stievano, L.; Giorgetti, M. Operando XAFS and XRD study of a Prussian blue analogue cathode material: Iron Hexacyanocobaltate. Condens. Matter 2018, 3, 36. [CrossRef]

14. Wu, J.; Li, Q.; Sallis, S.; Zhuo, Z.; Gent, W.E.; Chueh, W.C.; Yan, S.; Chuang, Y.D.; Yang, W. Fingerprint oxygen redox reactions in batteries through high-efficiency mapping of resonant inelastic X-ray scattering. Condens. Matter 2019, 4, 5. [CrossRef]

15. Suzuki, K.; Barbiellini, B.; Orikasa, Y.; Go, N.; Sakurai, H.; Kaprzyk, S.; Itou, M.; Yamamoto, K.; Uchimoto, Y.; Wang, Y.J.; et al. Extracting the redox orbitals in Li battery materials with high-resolution X-ray Compton scattering spectroscopy. Phys. Rev. Lett. 2015, 114, 087401. [CrossRef] [PubMed]

16. Barbiellini, B.; Suzuki, K.; Orikasa, Y.; Kaprzyk, S.; Itou, M.; Yamamoto, K.; Wang, Y.J.; Hafiz, H.; Yamada, R.; Uchimoto, Y.; et al. Identifying a descriptor for d-orbital delocalization in cathodes of Li batteries based on X-ray Compton scattering. Appl. Phys. Lett. 2016, 109, 073102. [CrossRef]

17. Hafiz, H.; Suzuki, K.; Barbiellini, B.; Orikasa, Y.; Callewaert, V.; Kaprzyk, S.; Itou, M.; Yamamoto, K.; Yamada, R.; Uchimoto, Y.; et al. Visualizing redox orbitals and their potentials in advanced lithium-ion battery materials using high-resolution $\mathrm{X}$-ray Compton scattering. Sci. Adv. 2017, 3, e1700971. [CrossRef]

18. Suzuki, K.; Kanai, R.; Tsuji, N.; Yamashige, H.; Orikasa, Y.; Uchimoto, Y.; Sakurai, Y.; Sakurai, H. Dependency of the charge-discharge rate on lithium reaction distributions for a commercial lithium coin cell visualized by Compton scattering imaging. Condens. Matter 2018, 3, 27. [CrossRef]

19. Suzuki, K.; Honkanen, A.P.; Tsuji, N.; Jalkanen, K.; Koskinen, J.; Morimoto, H.; Hiramoto, D.; Terasaka, A.; Hafiz, H.; Sakurai, Y.; et al. High-energy X-ray Compton scattering imaging of 18650-type lithium-ion battery cell. Condens. Matter 2019, 4, 66. [CrossRef]

20. Pussi, K.; Gallo, J.; Ohara, K.; Carbo-Argibay, E.; Kolen'ko, Y.V.; Barbiellini, B.; Bansil, A.; Kamali, S. Structure of manganese oxide nanoparticles extracted via pair distribution functions. Condens. Matter 2020, 5, 19. [CrossRef]

21. Kuriplach, J.; Pulkkinen, A.; Barbiellini, B. First-principles study of the impact of grain boundary formation in the cathode material $\mathrm{LiFePO}_{4}$. Condens. Matter 2019, 4, 80. [CrossRef]

22. Tuomisto, F.; Makkonen, I. Defect identification in semiconductors with positron annihilation: experiment and theory. Rev. Mod. Phys. 2013, 85, 1583. [CrossRef]

23. Barbiellini, B.; Kuriplach, J. Advanced characterization of lithium battery materials with positrons. In Journal of Physics: Conference Series; IOP Publishing: Bristol, UK, 2017; Volume 791, p. 012016.

24. Kmječ, T.; Kohout, J.; Dopita, M.; Veverka, M.; Kuriplach, J. Mössbauer spectroscopy of Triphylite $\left(\mathrm{LiFePO}_{4}\right)$ at Low temperatures. Condens. Matter 2019, 4, 86. [CrossRef]

25. Keshavarz, F.; Kadek, M.; Barbiellini, B.; Bansil, A. Electrochemical potential of the metal organic framework MIL-101 (Fe) as cathode material in Li-ion batteries. Condens. Matter 2021, 6, 22. [CrossRef] 
26. Lane, C.; Cao, D.; Li, H.; Jiao, Y.; Barbiellini, B.; Bansil, A.; Zhu, H. Understanding phase stability of metallic 1 T-MoS 2 anodes for sodium-ion batteries. Condens. Matter 2019, 4, 53. [CrossRef]

27. Chiu, W.C.; Singh, B.; Mardanya, S.; Nokelainen, J.; Agarwal, A.; Lin, H.; Lane, C.; Pussi, K.; Barbiellini, B.; Bansil, A. Topological Dirac semimetal phase in Bismuth based anode materials for sodium-ion batteries. Condens. Matter 2020, 5, 39. [CrossRef] 